\title{
Users' Assessment on Interior Environment of a Hospital Outpatient Unit in Malaysia
}

\author{
Zanariah Abu Samah, Norhati Ibrahim, Mohd Hanif Abd Wahab \\ Faculty of Architecture, Planning \& Surveying, \\ Universiti Teknologi MARA Shah Alam 40450, Malaysia \\ zanari02@salam.uitm.edu
}

\begin{abstract}
Assessment on the physical design of healthcare facilities from the perspective of the patient and their family members (user) is the method to understand their expectation, preferences and experiences. This paper reports the study conducted on an outpatient unit in Malaysia, focusing particularly on the interior design characteristics. The study adopted post occupancy evaluation technique that combines baseline analysis, occupancy survey and walkthrough observation methods. The study findings indicate that the case study, which has served the public for more than 20 years, is performing moderately on all interior design aspects. Users' assessments did not score any of the facility "good" in terms of their interior quality, suggesting the desire for improvement to the current facility.
\end{abstract}

Keyword: Quality design, Interior design aspect, Outpatientfacilities, Post- occupancy evaluation

eISSN 2514-751X @ C 2018. The Authors. Published for AMER ABRA cE-Bs by e-International Publishing House, Ltd., UK. This is an open access article under the CC BY-NC-ND license (http://creativecommons.org/licenses/bync-nd/4.0/). Peer-review under responsibility of AMER (Association of Malaysian Environment-Behaviour Researchers), ABRA (Association of Behavioural Researchers on Asians) and cE-Bs (Centre for EnvironmentBehaviour Studies), Faculty of Architecture, Planning \& Surveying, Universiti Teknologi MARA, Malaysia.

DOI: https://doi.org/10.21834/aje-bs.v3i7.271 


\subsection{Introduction}

In many parts of the world, demand for inpatient care has continued to reduce from year to year, and correspondingly the trend is towards increased reliance on outpatient healthcare (Carr, 2011). Likewise in Malaysia, the statistics has shownsimilardrasticincrement(MOH, 2009) which prompted the government to plan and build more new outpatient centres (Bernama, 2009). It is timely to assess the current state of outpatient facilities in the country to understand how well they serve the users.

Hospital outpatient service is a vital component in a medical care delivery. The facility that houses these services in the public hospitals in Malaysia is commonly referred to as Outpatient Unit. It provides primary care that focuses on preventive and public health care services. Subsidized by the government these facilities serve and appeal especially to the economically disadvantaged population.

Assessment of occupied buildings is essential to reveal design solutions that work as well as those that do not. It has been observed that assessment of outpatient facilities has remained unexplored as health care researches have focused mainly on acute and inpatient care (Preiser et al., 2009). As a contribution to fill this void, Preiser et al. (2009) conducted 5 case studies of community outpatient facilities in the USA. The study outcome was a design guide that is patients-cantered, providing health care environment which articulate issues relating to site planning, wayfinding, amenities, and the internal deployment of diagnostic and treatment functions.

As observed by Franklin et al. (2008) there have been few attempts to identify the performances of individual elements of physical environments (Franklin et al, 2008). While there are some foreign researches focusing on the waiting time, few have examined on the interior design characteristic which supportthe clinical process atthe outpatientarea. This paper reportsa postoccupancy study conducted on an outpatientunitin Malaysia, focusing particularly on the interior design characteristics. It serves as an initial step towards collating performance studies for the purpose of deriving an evident-based design guide for outpatient care interior architecture.

\subsection{Literature Review}

The definition and aspects of quality interiors have been described by many. According to Ching (2005), interior spaces within buildings are defined by the architectural elements of structure and enclosures which include floors, ceilings, walls, windows, doorways, and stairways. Interior elements are fit for visual and functional purposes that incorporate aspects of materials, construction, and technology. They make the interior spaces habitable-functional fit, aesthetically pleasing and psychologically satisfying for activities. In a similar tone, the American Society of Interior Design (ASID) describes the essence of Interior Design as functional, as well as an enhancement of the quality of life and culture of the occupants. Interior Design Manual (2008) elaborates further that the quality dimensions of interior design are to include productivity, health protection, safety and welfare of the space users. 
Ulrich (1991) opined that healthcare interiors are designed primarily with functional emphasis that tends to create an environment that negates the psychological needs of patients, visitors, and staff. The results are facilities which he regards to be psychologically "hard" that could be stressful to users. According to Dijkstra etal. (2006) design conditions that promote the betterment of users' health and wellbeing should include the use of colour, furniture, application of art and lighting. Referring to good quality interior environment as healing spheres, Ghazali and Abbas (2011) recommend a more comprehensive consideration to create healing interior, which include safety, ergonomics, colour, artwork, lighting, outside view, furniture and furnishings, ambience, and therapies.

\subsection{Methodology}

Many past researches have used Post Occupancy Evaluation (POE) technique to assess performance of occupied buildings especially health projects, for example, Carthey (2006) and Preiser (2009). Approaches to POE studies varied according to the intensity of the investigation (Presier, 1989) due to the time frame (Isaac et al. 2009), its purpose (Vischer, 2001) and availability of fund. This research employed this technique to gather information of the facility and feedback from users. Taking an indicative approach, this paper presents the initial results. Data was collected in three stages:

Stage 1: Background information and design characteristics, gathered from Head of Outpatient Unit and personnel. Drawings of the Unit layout were analyzed and diagramming drawn.

Stage 2: Walkthrough observations were conducted for two days duration recorded using note pad and taking photograph.

Stage 3: Feedback from patients and visitors was gathered using occupant survey form. A questionnaire for this survey was formulated through the process of review and modification of several past user satisfaction survey form particularly by Picker Institute, USA and Institute for Research in Construction (National Research Council Canada). The questions were narrowed down, focusing on interior design aspects clustered as space planning, ergonomics, accessibility, wayfinding, material and finishes, colour, lighting, furniture and safety. The rating scale is 1: worst, 2: bad, 3: neutral, 4: good and 5: best.

\section{Clinic Background}

The case study (referred to in this paper as RUKA 1), is a component of an outpatient unit of a government hospital in Malaysia. The hospital was established in 1987 and provided medical care for the Klang valley area. According to 2009 Annual Report the hospital served a total number of 879,862 outpatients and 466,977 inpatients. This clinic alone had served 139,317 of patients in 2009. Typically a patient seeking for treatment will go through the process of registration, waiting prior to consultation with the doctor, and a second wait to collect the medicine. There are five main areas: drop off, registration counter, waiting area, consultation rooms and pharmacy. Since its operation, the facility has attracted a growing number of patients annually, however, there has not been extensive renovation performed on the facility 
to accommodate this change.

\section{Survey Analysis}

A total of 401 patients responded to this survey. The survey was conducted in the month of January and February 2011. Respondents comprise a good mix of the three ethnic groups in Malaysia - Malay, Chinese, and Indian.

Table 1: Overall Scoring for Survey Items

\begin{tabular}{|c|c|c|c|c|c|c|c|c|}
\hline & \multicolumn{7}{|c|}{ Healthcare Facilities } \\
\hline & & \multirow{2}{*}{\begin{tabular}{|l} 
rop off \\
3.39 \\
\end{tabular}} & $\begin{array}{l}\text { gistration } \\
\text { Counter }\end{array}$ & $\begin{array}{l}\text { aiiting } \\
\text { Area }\end{array}$ & sultation Room & Pharmacy & \multicolumn{2}{|c|}{$\begin{array}{c}\text { Toilet Pverall } \\
\text { mean }\end{array}$} \\
\hline \multirow{9}{*}{ 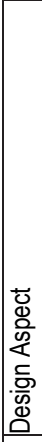 } & Space Planning & & 3.36 & 3.20 & 3.50 & 3.29 & 3.4 & 3.4 \\
\hline & Accessibility & 3.44 & 3.65 & 3.52 & 3.45 & 3.29 & 3.68 & 3.4 \\
\hline & Ergonomics & 3.33 & 3.21 & 3.33 & 3.24 & 3.27 & 2.99 & 3.2 \\
\hline & Way Finding & 3.69 & 3.24 & 3.25 & 3.32 & 3.26 & 3.22 & 3.3 \\
\hline & Safety & 3.02 & 3.12 & 3.00 & 3.3 & 3.1 & 2.69 & 3.0 \\
\hline & Colour & 2.93 & 2.96 & 3.06 & 3.21 & 3.06 & 3.04 & 3.0 \\
\hline & Lighting & 3.7 & 3.60 & 3.27 & 3.45 & 3.30 & 3.43 & 3.5 \\
\hline & Comfort & 3.29 & 2.74 & 3.27 & 3.35 & 3.31 & 3.17 & 3.2 \\
\hline & \begin{tabular}{|l} 
Material \& \\
Finishes
\end{tabular} & 3.19 & 2.98 & 3.11 & 3.2 & 3.16 & 2.87 & 3.1 \\
\hline & Overall mean & 3.3 & 3.2 & 3.2 & 3.3 & 3.2 & 3.2 & 3.2 \\
\hline
\end{tabular}

Notes: Rating scale, $1=$ Worst, $2=$ Bad, $3=$ Neutral, $4=$ Good, $5=$ Best.

Scorings below neutral $(<3)$ are highlighted in bold.

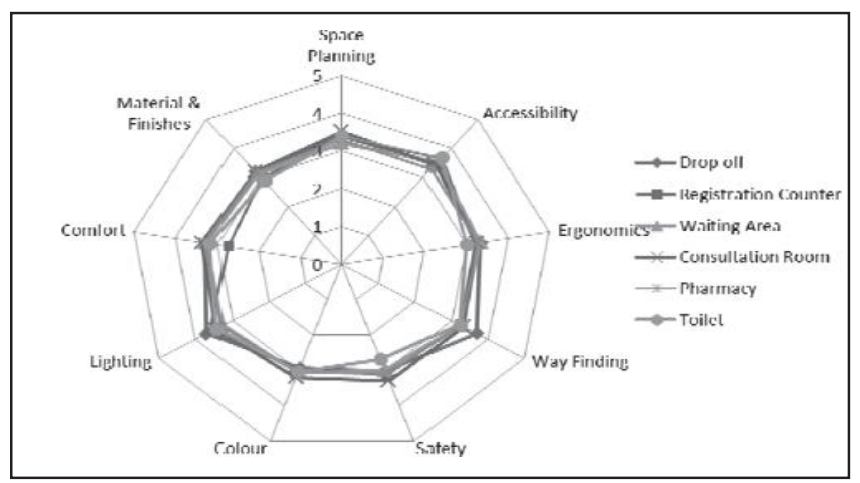

Figure 1: Overall Rating According to each Design Aspect for the Respective Spaces

As illustrated in Table 1 and Figure 1, the results indicate that a majority of the 
respondent rated the design aspects of each area within the neutral range with an average rating between 3.17 and 3.23. None of the spaces received 'good' and above rating (above 4). In terms of comfort, the registration counter area scored the lowest (2.74) and the consultation rooms scored highest (3.35). On the overall, the registration area and toilet area were scored lowest whereby 3 out of the 9 design aspects were rated below neutral. Relatively waiting area, consultation room and pharmacy areas received better scoring as they received above neutral scoring for all design aspects. Design aspects that received highest rating were lighting (3.5), followed by space planning (3.4), accessibility (3.4) and way finding (3.3). Ergonomic (3.2), comfort (3.2), safety (3.0), finishes \& materials (3.1) and color (3.0) were rated fair.

Based on this result, it can be concluded that patients and visitors find the overall performance of the facility to be acceptable but fair in meeting their satisfaction needs.

\section{Walkthrough Observation}

Observations and commentaries of the facility are summarised in the following table.

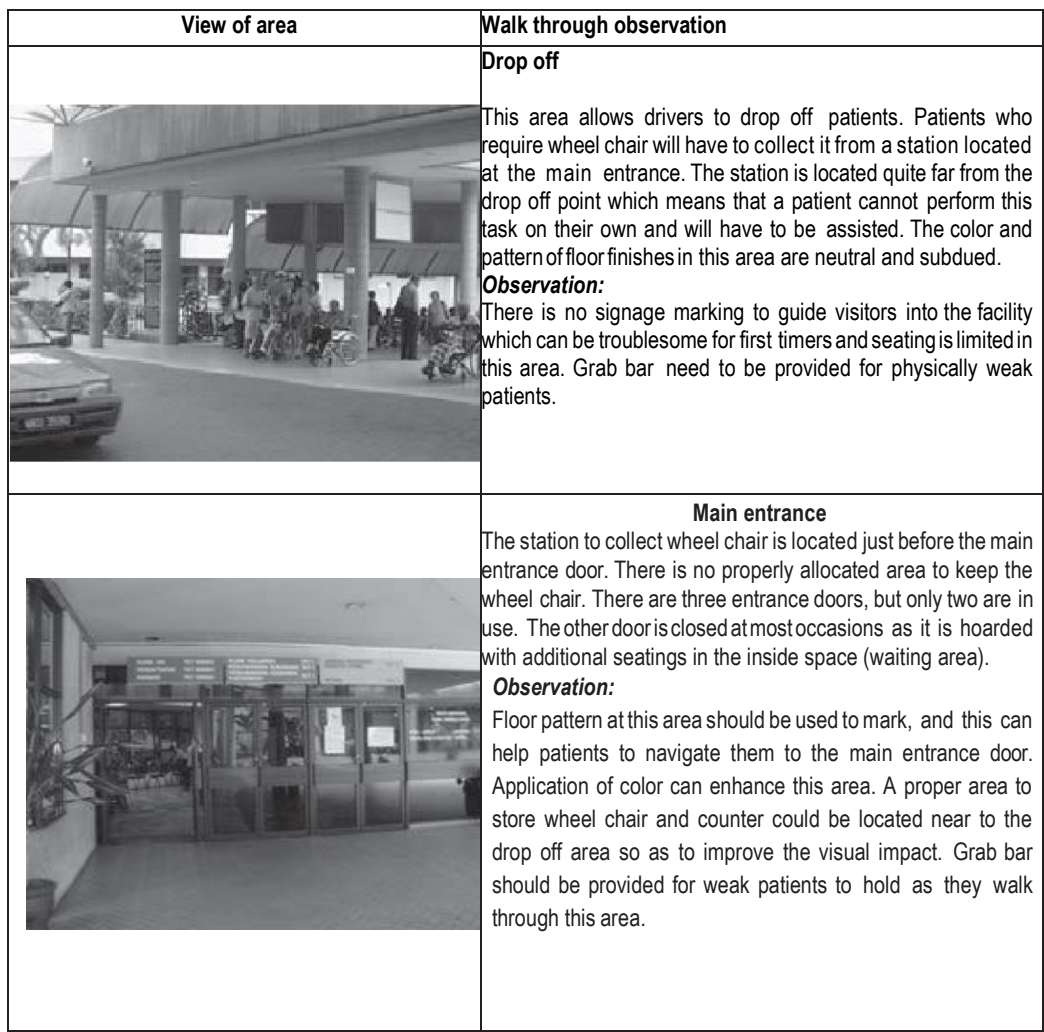




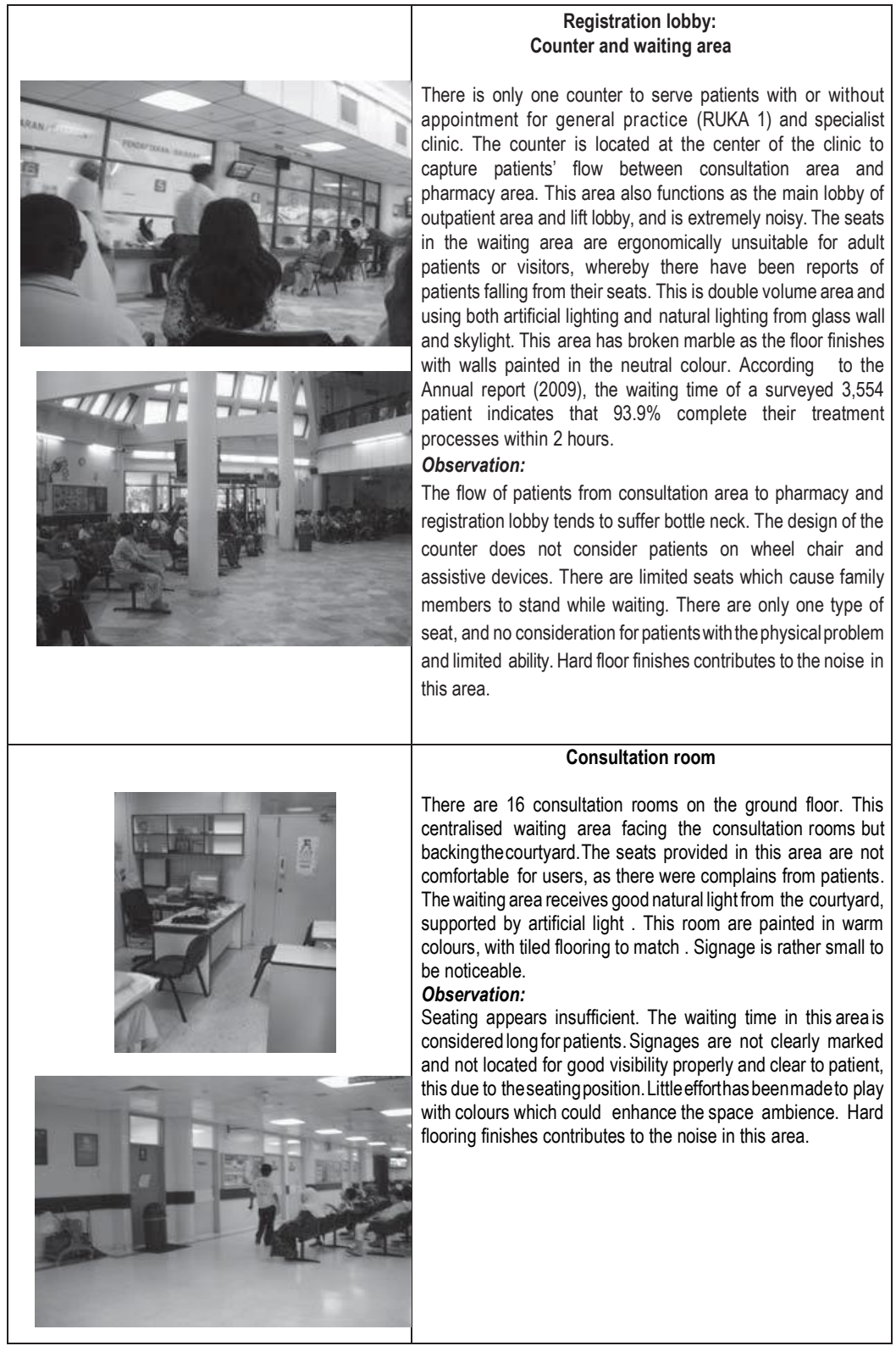




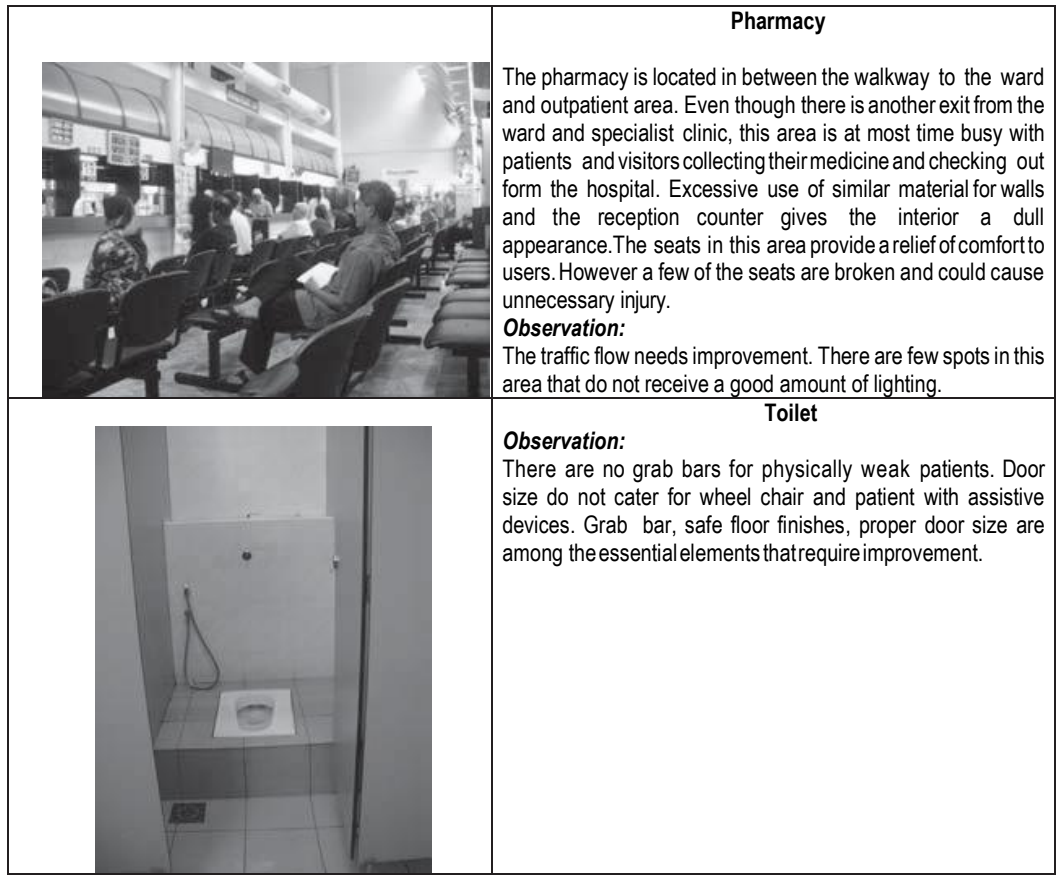

\subsection{Conclusion}

RUKA 1 was built and has served the public for more than 20 years. In this study the users' satisfaction feedback and observational survey provide evidence that, on the overall, the facility performs moderately on all interior design criteria. Users' assessments did not score any of the facility "good" in terms of their interior quality, suggesting the desire for improvement to the current facility. The research reviewed key interior design aspects and suggested key potential points for facility improvement based on the data findings.

The research used post occupancy evaluation technique as the method to determine the performance of a built facility based on users' satisfaction and experiences. Plan analysis was used as a guide in the study of space planning and how users experience the whole clinical process. The walk through observational technique provided a closer investigation to reveal micro aspects of interior design that could be further improved to serve the patients better. This supports Stern's (2003) recommendation on the importance for deeper understanding on the requirements, expectations, preferences, and experiences of consumers in order to achieve high-quality performance of designed spaces. Although the Post Occupancy study method has been extensively used in many projects in other countries, its use in Malaysia and other South East Asia countries are limited.

The patient survey has helped to identify the current performance of one case study of 
an outpatient unit in a Malaysia public hospital. The study concur with past studies that regard feedback from users as a critical component that necessitates ongoing documentation for translation into design information to assist designers and decision makers to better contribute towards higher quality care (Stern, 2003). As Malaysia prepares itself to become a fully developed nation, the quality of its health care facilities that care for the health and wellbeing of the general public is an area of study that crucially require careful investigation and enhancement. The current research took an indicative approach in studying only one case study. More Post Occupancy Evaluation of investigative nature is needed to enable the formulation of quality interior design guide for outpatient units in the tropics.

\section{Acknowledgment}

The authors wish to express our heartfelt gratitude towards UMMC for their full support and cooperation, as well as to the Universiti Teknologi MARA for financing the research.

\section{References}

Bernama September 2009: More ambulatory care centres under $10^{\text {th }}$ Malaysian Plan.

Carr, R. F. (2010). Outpatient Clinic. Whole Building Design Guide (WBDG). http://www.wbdg.org/design/outpatient.php

Carthey, J. (2006). Post Occupancy Evaluation: Development of a Standardised Methodology for Australian Health Projects. The International Journal of Construction Management, 57-74.

Ching, D., K. (2005). Interior Design Illustrated. New Jersey: John Wiley \& Sons. Chapter $1 \& 2$.

Dijkstra, K. (2006) Physical environmental stimuli that turn healthcare facilities into healing environments through psychologically mediated effects: systematic review. Joumal of Advanced Nursing. 56(2)166-181.

Dijkstra, K. (2009)Understandinghealingenvironments: Effects of physical environmental stimulation patients' health and well-being. Faculty of Behavioural Sciences, University of Twente, Enschede, Netherlands. 9-138.

Franklin, B., Bridget S. and Parson K. (2008). Ambulatory Facility Design and Patients' Perceptions of Healthcare Quality, Health Environments Research \& Design Journal.

Ghazali, R., \& Abbas, M. Y. (2011). Pediatric Wards: Healing Environment Assessment. Asian Journal of EnvironmentBehaviourStudies (ajE-Bs), 2(4), pp. 63-76.

Health Care Design \& The Picker Institute.Patient-Centred Environmental Checklist 1999.

Issac A. Mier, Yaakov Garb, Dixin Jiao and Alex Cicelsky (2009) Post Occupancy Evaluation: An Inevitable Step Toward Sustainability, Advances in Building Energy Research, Vol 3, pp 189-220.

Preiser, W., F., E., Verderber, V., and Basttisto, D. (2009) Assessment of Health Center Performance: Towards the Development of Design Guidelines, International Journal of Architecture Research.

Stern, L.A., Mac Rae S., Gertis M., Harrison T., Fowler E., Edgman-Levitan S., Walker J., and Ruga W., (2003) 
Abu Samah, Z., et.al. / Asian Journal of Environment-Behaviour Studies (ajE-Bs), 3(7) Mar / Apr 2018 (p. 179-187)

Understanding The Consumer Perspective To Improve Design Quality, Journal of Architectural and Planning Research. 16-28.

Ulrich, R. (1991)Effects of InteriorDesign on Wellness: Theory and Recent Scientific Research, Journal of Healthcare Interior Design.97-109.

Ulrich, R. (2002) Effects of Healthcare Environmental Design on Medical Outcomes, Journal International Academy for Design and Health. 49-59.

Vischer, J. (2001). "Post-Occupancy Evaluation: A Multifaceted Tool for Building Improvement", Learning from our buildings: a state-of-the- practice summary of post-occupancy evaluation. 